\title{
Enhanced Red Emission in Ultrasound-Assisted Sol-Gel Derived ZnO/PMMA Nanocomposite
}

\author{
Van-Tuan Mai, ${ }^{1}$ Quang-Bac Hoang $\mathbb{D}^{2},{ }^{2}$ and Xuan-Dung Mai $\mathbb{D}^{2,3}$ \\ ${ }^{1}$ Department of Basic Sciences, Electric Power University, 235 Hoang Quoc Viet, Hanoi, Vietnam \\ ${ }^{2}$ Department of Chemistry, Hanoi Pedagogical University No. 2, Xuan Hoa, Phuc Yen, Vinh Phuc, Vietnam \\ ${ }^{3}$ Institute of Research and Development, Duy Tan University, 03 Quang Trung, Da Nang, Vietnam
}

Correspondence should be addressed to Xuan-Dung Mai; xdmai@hpu2.edu.vn

Received 6 July 2017; Revised 27 October 2017; Accepted 28 November 2017; Published 7 February 2018

Academic Editor: Marco Cannas

Copyright (c) 2018 Van-Tuan Mai et al. This is an open access article distributed under the Creative Commons Attribution License, which permits unrestricted use, distribution, and reproduction in any medium, provided the original work is properly cited.

Cost-effective methods for preparing $\mathrm{ZnO}$ nanostructures are of importance for the deployment of $\mathrm{ZnO}$ in many applications including $\mathrm{n}$-type conduits, catalysts, nanophosphor, and optoelectronics. Herein, we present a room-temperature sol-gel method with the aid of ultrasonication to prepare white-emitting $\mathrm{ZnO}$ nanoparticles (NPs). X-ray diffraction and electron microscopic analyses revealed that the size and shape of $\mathrm{ZnO}$ NPs can be controlled simply by changing the concentration of the $\mathrm{Zn}$ precursor. The $\mathrm{ZnO}$ NPs had a broad photoluminescence emission, ranging from $450 \mathrm{~nm}$ to $800 \mathrm{~nm}$, while their composite in PMMA matrix showed an enhancement in the red region induced by ZnO-PMMA interfacial band-bending effects. The results demonstrated herein promise a simple tool for control over size, shape, and emission of $\mathrm{ZnO}$ materials for diverse applications.

\section{Introduction}

Zinc oxide $(\mathrm{ZnO})$ is a n-type semiconducting material with a great application potential as electron conduit in (opto) electronic devices $[1,2]$, photocatalysts $[3,4]$, and photoluminescence materials $[5,6]$. There are several methods for the synthesis of $\mathrm{ZnO}$ nanostructures, including sol-gel method, controlled precipitation, solvothermal techniques, microemulsion, and sonochemical treatments [7]. Among them, sonochemical synthesis has been emerged as an efficient technique to prepare $\mathrm{ZnO}$ NPs of different shapes $[8,9], \mathrm{ZnO}$ polymer composites [10], and evenly doped $\mathrm{ZnO}$ NPs [11]. In the sonochemical synthesis, the application of an ultrasound with a frequency ranging from $15 \mathrm{kHz}$ to $10 \mathrm{MHz}$ induces the formation, growth, and implosive collapse of bubbles in the reaction mixture, also known as cavitations [12]. The collapse of bubbles induced by cavitations creates localized hotspots having extremely high temperature $(5000 \mathrm{~K})$, high pressure $(500 \mathrm{~atm})$, and rapid heating or cooling rate $\left(10^{9} \mathrm{~K} / \mathrm{s}\right)$. These extreme conditions enable highenergy chemical processes such as formation of radical and high-surface-area nanocrystals and efficient diffusion of ionic dopants into crystals forming doped nanocrystals while keeping the apparent reaction conditions at room temperature and atmospheric pressure.

Many important applications of ZnO NPs rely on their optical properties. While $\mathrm{ZnO}$ absorb efficiently UV light with photon energy greater than its bandgap, of about $3.3 \mathrm{eV}$, it usually emits both UV and visible light. The UV emission is assigned to band-to-band recombination between electrons and holes residing at the edges of conduction and valence band, respectively. The visible emission is usually attributed to various recombination pathways between photoexcited charges being trapped at defect states within the bandgap. Although the chemical origin of defect states is still controversial [5, 13-15], surface modification has been widely used to control over the visible emission of $\mathrm{ZnO}$, especially in $\mathrm{ZnO}$ nanostructures. Patrick Felbier and coworkers controlled air exposure of plasma-synthesized $\mathrm{ZnO}$ nanoparticles (NPs) to switch the emission from UV to yellow or green with a quantum yield of $60 \%$ [5]. The changes in photoluminescence properties were reasoned to surface $\mathrm{OH}$ groups created during the exposure to air. Tang et al. [16] varied the density of oxygen vacancy and 
interstitial $\mathrm{Zn}$ on the surface of sol-gel derived $\mathrm{ZnO}$ NPs via adjusting $\mathrm{pH}$ of initial sol solution to change the emission color from green to orange. In addition to popularly observed green and orange emission, red emission $\mathrm{ZnO}$ NPs have been rarely reported $[17,18]$. These representative examples point out a mean of control over the emission color of $\mathrm{ZnO}$ but also imply the high sensitivity of $\mathrm{ZnO}$ luminescence to environment.

Incorporation of $\mathrm{ZnO}$ into polymer matrix is a convenient way to stabilize the PL properties of $\mathrm{ZnO}$ and to add new functionalities to the polymer $[6,13,19]$. Herein, we observed unexpectedly that poly(methyl methacrylate) (PMMA) matrix quenches the original green-orange emission but enhances red emission of $\mathrm{ZnO}$ NPs. This result provides a simple ultrasound-assisted mixing method for fabrication of red-emitting composites for lighting applications.

\section{Experimental}

2.1. Synthesis of $\mathrm{ZnO}$ Nanoparticles. An calculated amount of zinc acetate dihydrate (98\%, Aldrich) was added into a flask containing a mixture of $95 \mathrm{ml}$ ethanol (99.5\%, Aldrich) and $5 \mathrm{ml}$ DI water under $\mathrm{N}_{2}$ environmental conditions. The mixture was then magnetically stirred to form a clear solution with a concentration ranging from 0.01 to $0.1 \mathrm{M}$. pH of the solution was adjusted to 9.5 by adding $\mathrm{NH}_{3}$ solution ( $7 \mathrm{M}$, Aladdin Chemical). The reaction flask was connected with an ultrasonic Ti tip and placed into a thermostatic tank at $70^{\circ} \mathrm{C}$. After being sonicated at a frequency of $20 \mathrm{kHz}$ for two hours, the mixture was centrifuged at a speed of $8000 \mathrm{rpm}$ to precipitate $\mathrm{ZnO}$ NPs, which were further rinsed with excess DI water and dried to perform powder $\mathrm{ZnO}$.

2.2. Synthesis of ZnO-PMMA Composites. Powder $\mathrm{ZnO}$ and PMMA $\left(M_{n}=54,000\right.$, Aldrich $)$ were dispersed separately in dichloromethane by means of sonication to perform crude solutions. A calculated amount of $\mathrm{ZnO}$ crude solution was poured into PMMA solution and allowed to mix to form a homogenous composite solution with varied $\mathrm{ZnO}$ weight percentage. The solution was then poured on glass substrates, flatted by a glass tube, and dried to form composite membranes.

2.3. Characterizations. Crystalline structure of $\mathrm{ZnO}$ was studied by X-ray diffraction patterns recorded on a Bruker D5005 diffractometer. The morphology of ZnO NPs and $\mathrm{ZnO}-\mathrm{PMMA}$ composites was investigated by scanning electron microscope (SEM) images which were obtained on a FEI NanoSEM 450. Transmittance electron microscope (TEM) images were obtained on JEOL TEM 4510 microscope. Optical properties of $\mathrm{ZnO} \mathrm{NPs}$ and the resultant composites were characterized by UV-Vis absorption (Varian Cary 500 spectrometer) and photoluminescence (PL) measurements. For PL measurement, samples were excited with laser with a wavelength of $325 \mathrm{~nm}$, and the PL signal was recorded by a Si-CCD detector-equipped monochromator (Horiba iHR550).

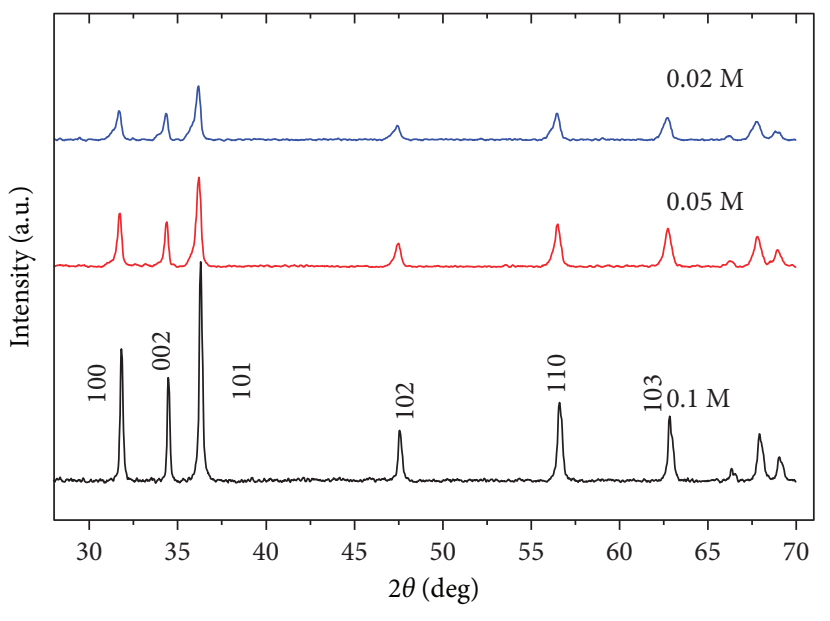

FIgURE 1: X-ray diffraction patterns of $\mathrm{ZnO}$ nanoparticles when varying zinc acetate concentration.

\section{Results and Discussion}

X-ray diffraction patterns of $\mathrm{ZnO}$ NPs obtained when varying the initial concentration of zinc acetate are shown in Figure 1. All samples exhibit common diffractions peaking at 2 theta of $31.7^{\circ}, 34.5^{\circ}, 36.3^{\circ}, 47.6^{\circ}, 56.7^{\circ}$, and $63.9^{\circ}$, which correspond to the reflection, respectively, from (100), (002), (101), (102), (110), and (103) lattice plans of $\mathrm{ZnO}$ wurtzite structure (JCPDS-36-1451).

The size of crystalline domains within ZnO NPs was estimated by using Scherrer's equation: $D=k \lambda /(\beta \cos (\theta))$, where $\lambda=0.1542 \mathrm{~nm}$ is the wavelength of incident X-ray, $\beta$ is the full width at half maximum of the (101) peak, $\theta$ is the Bragg diffraction angel, and $k=0.9$ is the constant [20]. It was $45 \mathrm{~nm}, 35 \mathrm{~nm}$, and $29 \mathrm{~nm}$ for $\mathrm{ZnO}$ NPs synthesized from $0.1 \mathrm{M}, 0.05 \mathrm{M}$, and $0.02 \mathrm{M}$ zinc acetate solutions, respectively. These domain sizes were much smaller than the dimension of $\mathrm{ZnO}$ NPs observed in SEM images shown in Figure 2. Most of $\mathrm{ZnO}$ NPs synthesized from zinc acetate $0.1 \mathrm{M}$ solution have a rod-like hexagonal structure with $1 \mu$ (width) $\times 2.5 \mu$ (length) dimension (Figure $2(\mathrm{a})$ ). When the concentration of precursor solution decreased, the $\mathrm{ZnO}$ NPs turned into spherical with a diameter of $300 \pm 50 \mathrm{~nm}$ as shown in Figures 2(b) and 2(c). The results suggest a simple tool, that is, varying the concentration of precursor solution, to control over the morphology and size of sol-gel derived $\mathrm{ZnO}$ NPs. In line with X-ray analysis that ZnO NPs had crystalline domains of $29 \div 45 \mathrm{~nm}$, the TEM image of a $\mathrm{ZnO}$ particle shown in Figure 2(d) reveals many connecting $\mathrm{ZnO}$ domains within one particle.

The extreme reaction conditions, for example, high temperatures, pressure, and heating and cooling rates, induced by collapse of microbubbles in ultrasound irradiated solution have been utilized to prepare various $\mathrm{ZnO}$ nanostructures $[8,21,22]$. Ultrasonication conditions (intensity, duration, temperature, and duty cycle) and chemical composition (solvent and additives) are proposed to be the key parameters of controlling over the morphology of $\mathrm{ZnO}$ nanostructures. In the present study, we observed that $\mathrm{ZnO}$ changed from spherical particle to hexagonal rod-like 


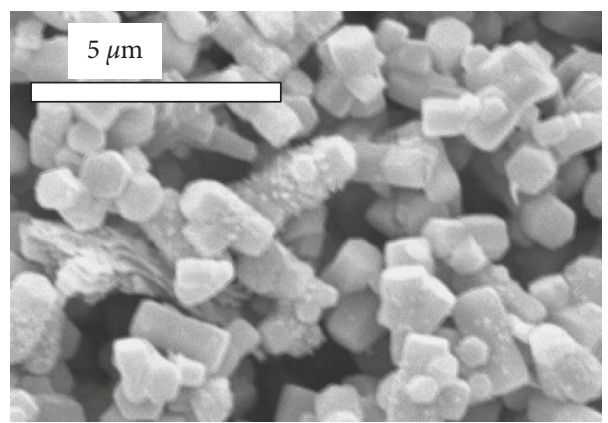

(a)

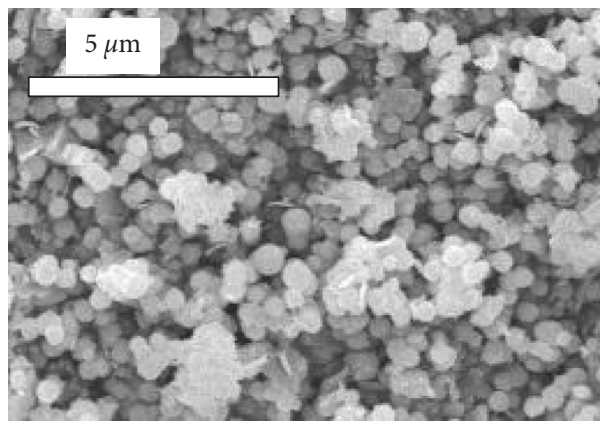

(c)

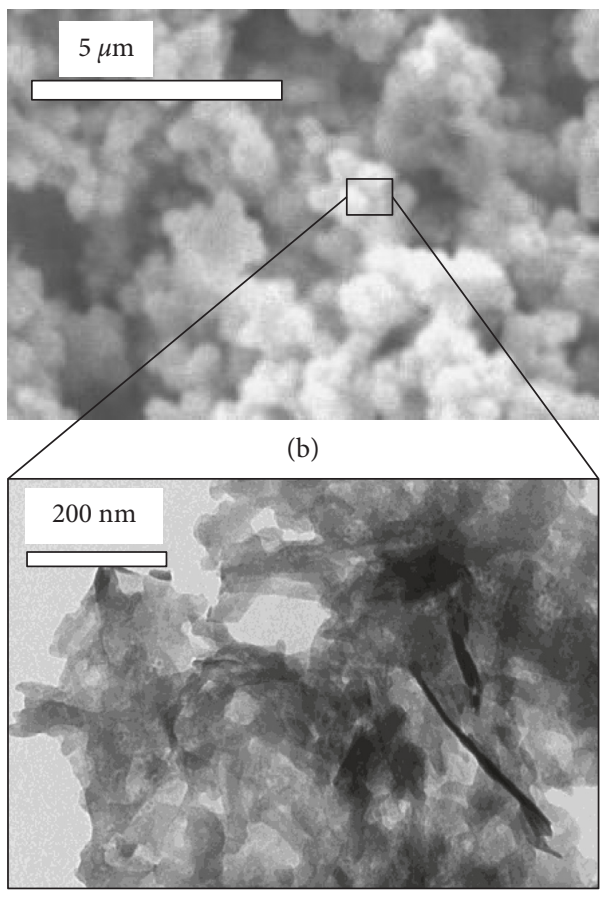

(d)

Figure 2: SEM images of $\mathrm{ZnO}$ nanoparticles obtained by using (a) $0.1 \mathrm{M}$, (b) $0.05 \mathrm{M}$, and (c) $0.02 \mathrm{M}$ zinc acetate. (d) TEM image of ZnO NPs.

structure when only the concentration of zinc acetate increased from 0.02 to $0.1 \mathrm{M}$ (Figure 2). The formation of $\mathrm{ZnO}$ nanostructures can be represented as follows:

$$
\begin{aligned}
\mathrm{NH}_{3}+\mathrm{H}_{2} \mathrm{O} & \rightarrow \mathrm{NH}_{4}^{+}+\mathrm{OH}^{-} \\
\mathrm{Zn}\left(\mathrm{OOCH}_{3}\right)_{2}+2 \mathrm{OH}^{-} & \rightarrow \mathrm{Zn}(\mathrm{OH})_{2}+2 \mathrm{CH}_{3} \mathrm{COO}^{-} \\
\mathrm{Zn}(\mathrm{OH})_{2}+4 \mathrm{NH}_{3} & \rightleftarrows\left[\mathrm{Zn}\left(\mathrm{NH}_{3}\right)_{4}^{2+}\right]+2 \mathrm{OH}^{-} \\
\mathrm{Zn}(\mathrm{OH})_{2} & \rightarrow \mathrm{ZnO}+\mathrm{H}_{2} \mathrm{O}
\end{aligned}
$$

At $\mathrm{pH}$ of 9.5 and temperature of $70^{\circ} \mathrm{C}$ (see Experimental), $\mathrm{Zn}(\mathrm{OH})_{2}$ are the major soluble species of $\mathrm{Zn}^{2+}$ complexes (2) [22]. The presence of $\mathrm{NH}_{3}$ (3) and ultrasound irradiation inhibited fast aggregation of neutrally charged $\mathrm{Zn}$ $(\mathrm{OH})_{2}$ into amorphous solids. Furthermore, ultrasonication induced the condensation of $\mathrm{Zn}(\mathrm{OH})_{2}$ into $\mathrm{ZnO}$ nanocrystals according to (4). This process took part homogeneously in all the volume of reaction forming spherical $\mathrm{ZnO}$ NPs when the concentration of the zinc precursor was low, for example, 0.02 or $0.05 \mathrm{M}$. It was reported that the presence of $\mathrm{Zn}(\mathrm{OH})_{2}$ is a key factor for the growth of $\mathrm{ZnO}$ nanocrystals into hexagonal nanorods by adding $\mathrm{Zn}(\mathrm{OH})_{\mathrm{x}}$ complexes onto positively charged, Zn-terminated (0001) planes [22-24]. Similarly, when the concentration of the zinc precursor increased to $0.1 \mathrm{M}$, free $\mathrm{Zn}(\mathrm{OH})_{2}$ reacted with preformed spherical $\mathrm{ZnO}$ nanocrystals producing hexagonal rod-like structures as seen in Figure 2(a). The presence of $\mathrm{Zn}-\mathrm{OH}$ terminals on the surface of $\mathrm{ZnO}$ NPs needed for the growth of $\mathrm{ZnO}$ rod-like structures is supported by the FT-IR spectrum of $\mathrm{ZnO}$ shown in Figure 3(a). A broad absorption band centered at $3400 \mathrm{~cm}^{-1}$ and a shoulder at $1560 \mathrm{~cm}^{-1} \mathrm{can}$ be attributed to vibrations of $\mathrm{O}-\mathrm{H}$ bonds in either absorbed water or surface $\mathrm{Zn}-\mathrm{OH}$ groups, which is further supported by a shoulder at $1630 \mathrm{~cm}^{-1}$. A peak at $1385 \mathrm{~cm}^{-1}$ is resulted from $\mathrm{OH}^{-}$absorption of hydrogen-related defects [25].

Optical properties of $\mathrm{ZnO}$ NPs are summarized in Figures 3(b) and 3(c). ZnO NPs absorbs efficiently UV light with wavelength less than $400 \mathrm{~nm}$, demonstrating the UVblocking property. Direct bandgap of $\mathrm{ZnO}, E_{g}=3.18 \mathrm{eV}$, was determined by Tauc expression (inset in Figure 2(b)): $(\alpha h v)^{2}=B\left(h v-E_{g}\right)$, where $\alpha, h v$, and $B$ are the absorption coefficient, photon energy, and constant, respectively [26]. PL spectra of ZnO NPs shown in Figure 3(c) exhibit two distinct UV and visible emission regions. The UV emission is relatively narrow, maximizes at $385 \mathrm{~nm}$, and decreases in intensity when drying the ZnO NPs in the open-air conditions. The visible emission is broad, ranging from $450 \mathrm{~nm}$ to $800 \mathrm{~nm}$. Additionally, drying $\mathrm{ZnO} \mathrm{NPs}$ in air at middle temperatures, for example, $100^{\circ} \mathrm{C}$, quenches completely the UV emission while enhances the visible emission. The results promise the use of sol-gel derived $\mathrm{ZnO} \mathrm{NPs}$ as white-light phosphor in LED applications.

Morphology and optical properties of the solvent-mixed ZnO-PMMA composite are summarized in Figure 4. Composite membrane fabricated by a bar-coating method was relatively homogeneous with some white spots (Figure 4(a)). The SEM image shown in Figure 4(b) visualized at a white spot revealed aggregates of $\mathrm{ZnO}$ NPs with physical cracks. This phase segregation may be due to large aggregations of $\mathrm{ZnO}$ NPs that were still present in the solvent-mixing 


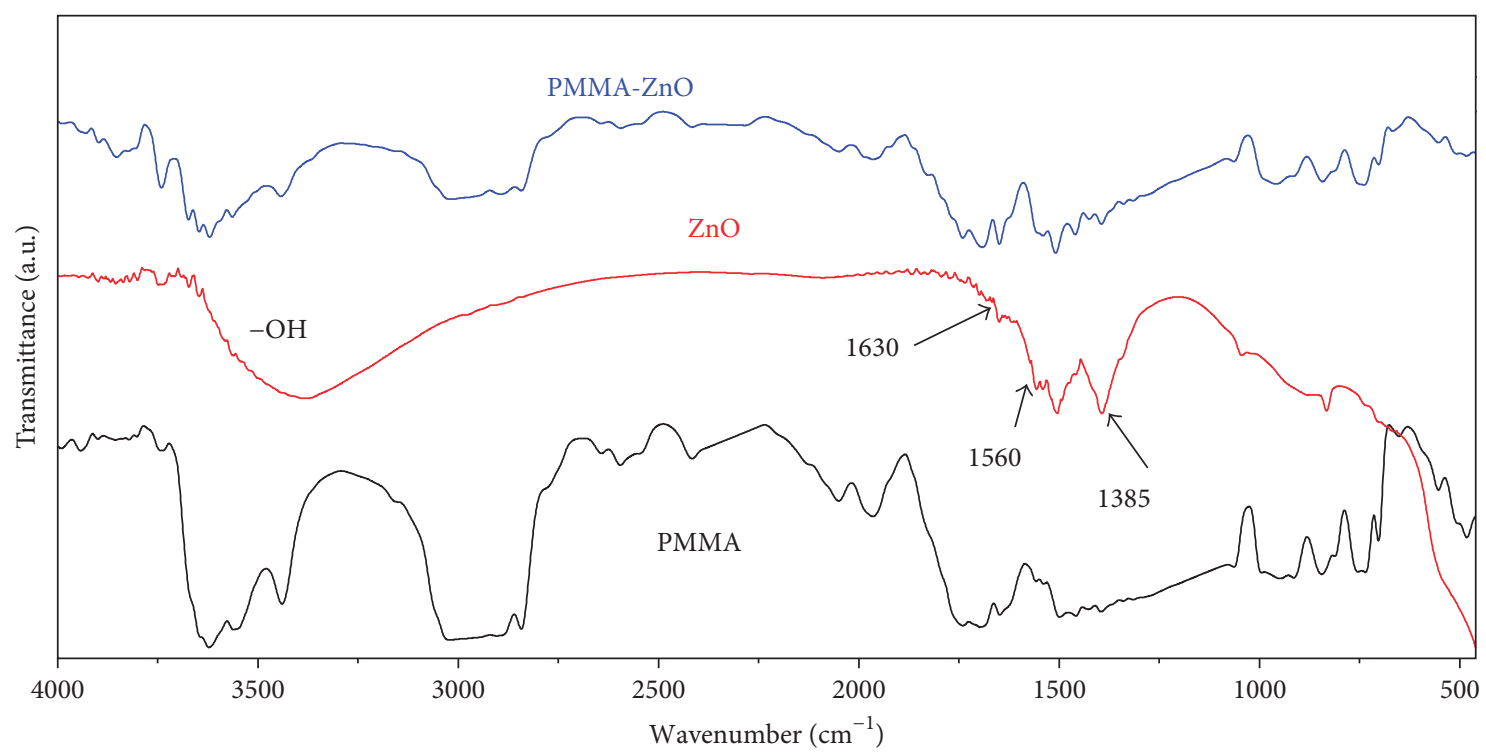

(a)
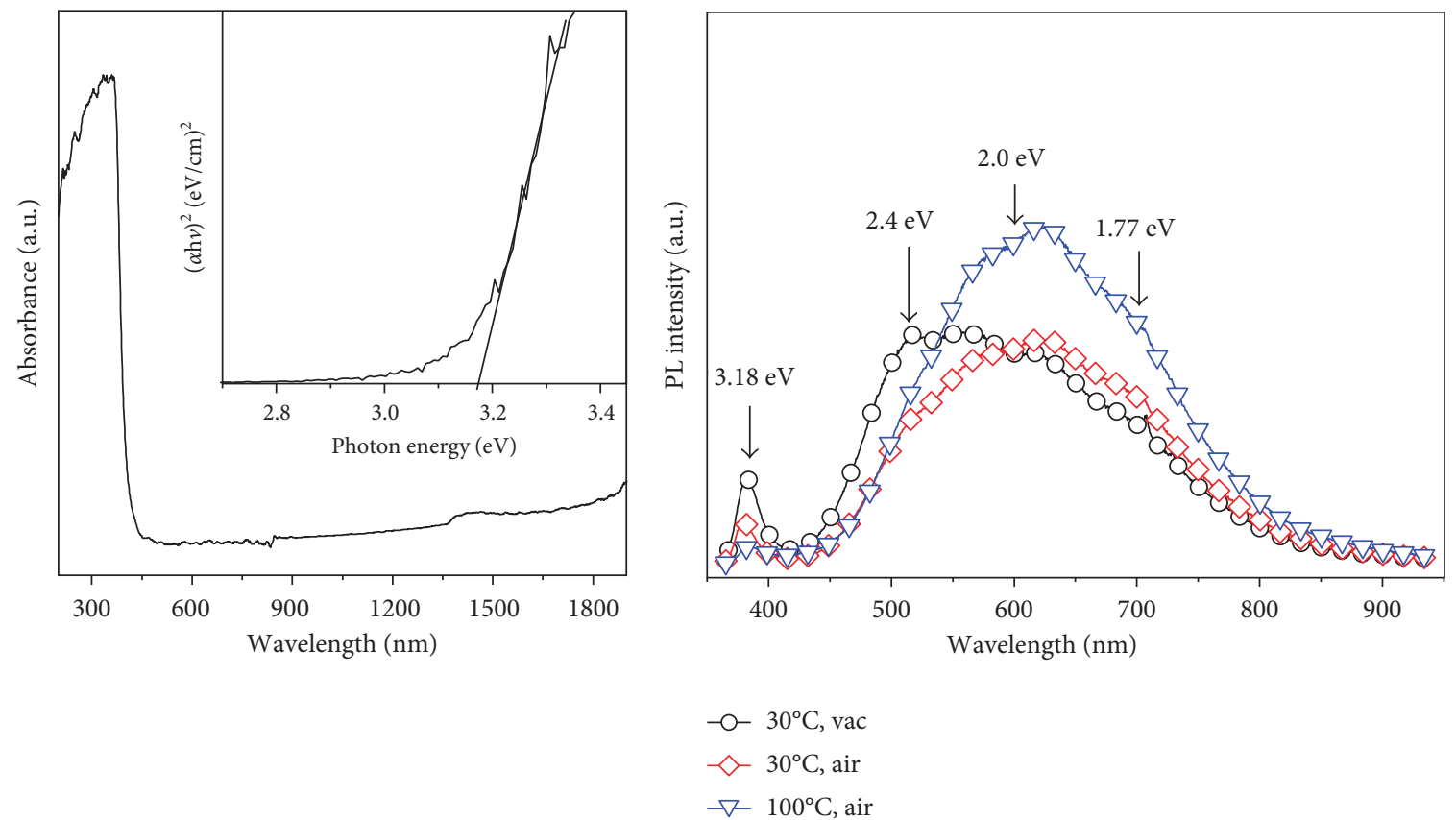

(b)

(c)

FIGURE 3: (a) FT-IR spectra and (b) UV-absorption. Inset: Tauc plot determining the bandgap of ZnO. (c) PL spectra of ZnO samples with different postdrying conditions $\left(\lambda_{\mathrm{ex}}=325 \mathrm{~nm}\right)$.

phase and difference in hydrophilicity between $\mathrm{ZnO}$ NPs and PMMA $[19,27,28]$. Due to this phase segregation, we restricted our study to $\mathrm{ZnO}$-PMMA composites with $\mathrm{ZnO}$ composition of less than 1 wt.\%.

$\mathrm{UV}-\mathrm{V}$ is absorption property of a $90 \mu$ thick $\mathrm{ZnO}$-PMMA membrane is shown in Figure 4(c). In addition to sharp UV absorbance that increased with $\mathrm{ZnO}$ content, the transmittance spectra exhibit a tail increasing gradually with wavelength. The absorbance in the UV region of the composite received from UV-blocking property of $\mathrm{ZnO}$. The absorption tail can be attributed to light-scattering effect derived from phase separation in the $\mathrm{ZnO}$-PMMA composite discussed earlier.

PL spectra of the ZnO-PMMA composite are shown in Figure $4(\mathrm{~d})$ in comparison with PMMA alone. Both PMMA and $\mathrm{ZnO}$-PMMA composites exhibit an intense and unsymmetrical peak at $390 \mathrm{~nm}$ probably due to unknown impurities. Unfortunately, this blue emission may overwhelm possible band-edge emission from $\mathrm{ZnO}$ NPs as seen in Figure 3(d). The 1 wt.\% ZnO-PMMA sample showed 


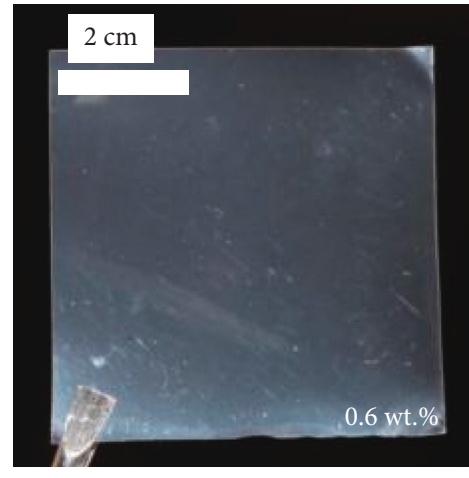

(a)

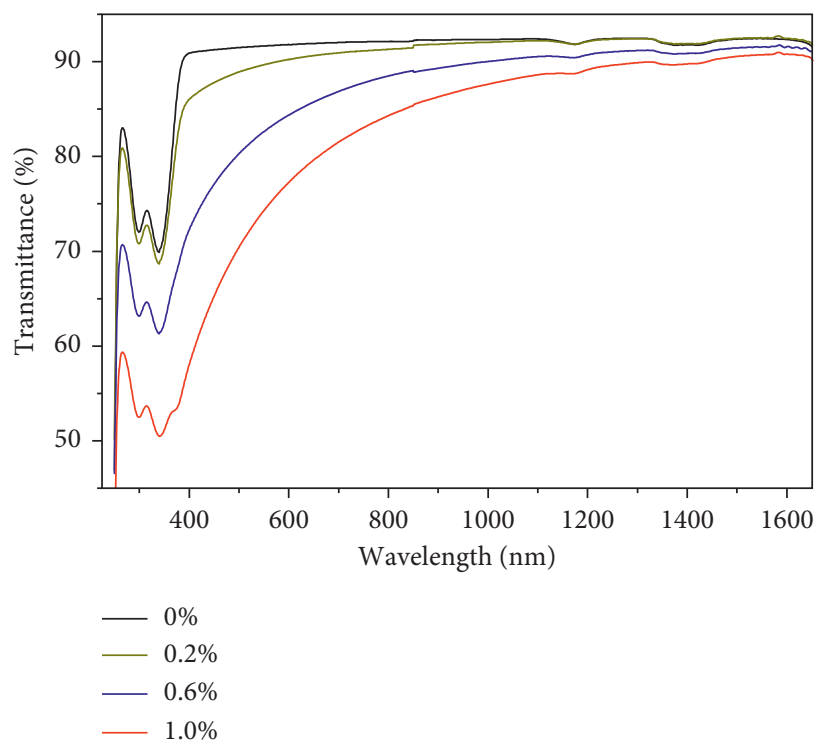

(c)

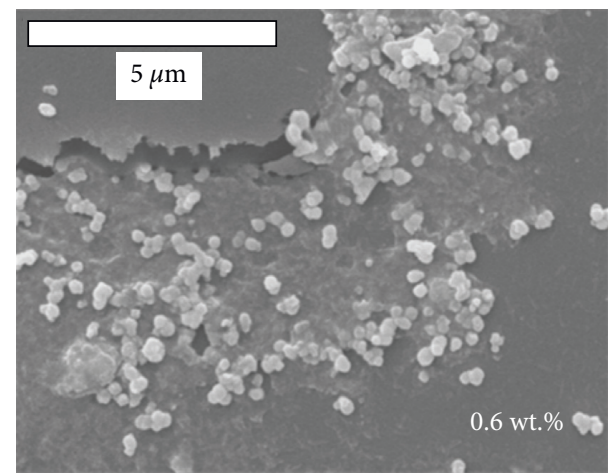

(b)

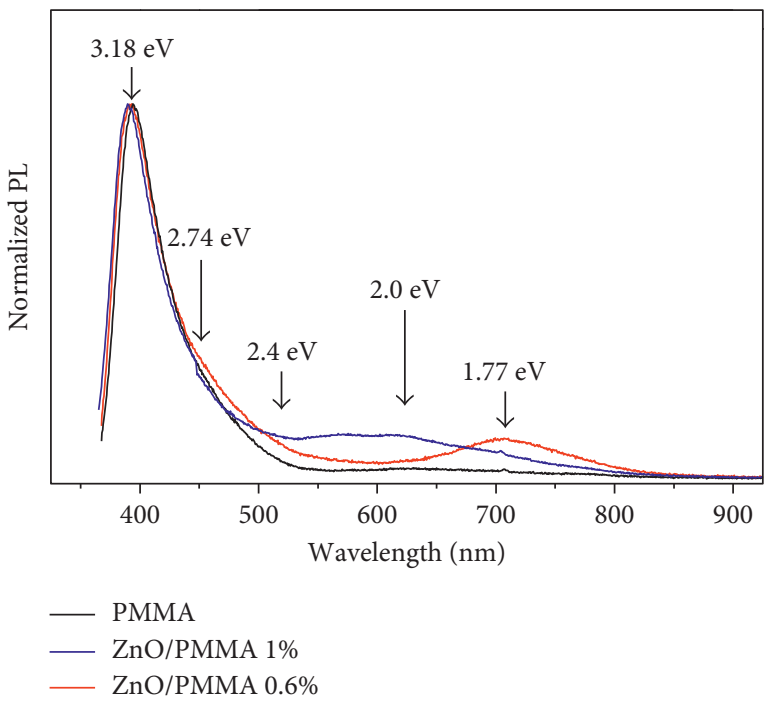

(d)

FIgUre 4: (a) A membrane picture; (b) SEM image; (c) UV-Vis absorption; (d) photoluminescence spectra of the ZnO-PMMA composite.

a combined PL feature between the UV-blue emission from PMMA matrix and the broad visible emission from $\mathrm{ZnO}$ powder (Figure 3(d)). Interestingly, when the content of $\mathrm{ZnO}$ NPs decreased to $0.6 \mathrm{wt}$.\%, only red emission centered at $702 \mathrm{~nm}$ was observed in the visible region. Further decreasing the content of $\mathrm{ZnO} \mathrm{NP}$ to $0.2 \mathrm{wt} \%$, the intensity of red emission was too low as compared with the UV-blue emission from PMMA matrix.

Visible emission is widely observed on $\mathrm{ZnO}$ nanostructures and has been assigned to the recombinations of photoexcited electrons-holes being trapped at defect states including oxygen vacancies $\left(V_{\mathrm{O}}\right)$, zinc interstitials $\left(I_{\mathrm{Zn}}\right)$, zinc vacancies $\left(V_{\mathrm{Zn}}\right)$, and their complexes $[2,6,14,16,17$, 20, 29-31]. Here, we put forward a plausible mechanism shown in Figure 5 to explain PL properties of the $\mathrm{ZnO}$ PMMA composite.

The presence of $I_{\mathrm{Zn}}$ defect states whose energy level is theoretical predicted to be near the conduction band minimum results in charged $I_{\mathrm{Zn}}^{+}$and $I_{\mathrm{Zn}}^{++}[32]$. Both $I_{\mathrm{Zn}}$ and
$V_{\mathrm{O}}$ related point defects have a high formation energy leading to their low concentrations in $\mathrm{ZnO}$. However, Coulomb interaction between $I_{\mathrm{Zn}}$ and $V_{\mathrm{O}}$ point defects efficiently reduces their formation enthalpy and results in a series of hybridized $I_{\mathrm{Zn}}^{*}$ and $V_{\mathrm{O}}^{*}$ states whose energies vary as a function of their mutual separation [33]. The existence of $I_{\mathrm{Zn}}^{*}$ related states was experimentally observed by UV-blue emission in $\mathrm{ZnO}$ NPs when excitation energies just below the energy gap were applied [31]. In the present study, we did not observe such UV-blue emission on ZnO NPs (Figure 3(c)), probably due to a high-energy excitation at $325 \mathrm{~nm}(3.81 \mathrm{eV})$. $I_{\mathrm{Zn}} / I_{\mathrm{Zn}}^{*}$ and $V_{\mathrm{O}}^{++}$related sates are localized about $0.1-0.6 \mathrm{eV}$ and $2.0 \mathrm{eV}$, respectively, below the conduction band minimum, and that $V_{\mathrm{O}}^{+}$states are aligned at about $2.4 \mathrm{eV}$ above the valence band maximum [30-32]. These defect states are depicted in Figure 5(a), and the energies are noted in Figures 3(c) and 4(d). In Figure 5(a), we tentatively assigned the green $(2.4 \mathrm{eV})$ emission to the recombination between photoexcited electrons being trapped at $V_{\mathrm{O}}^{+}$states 


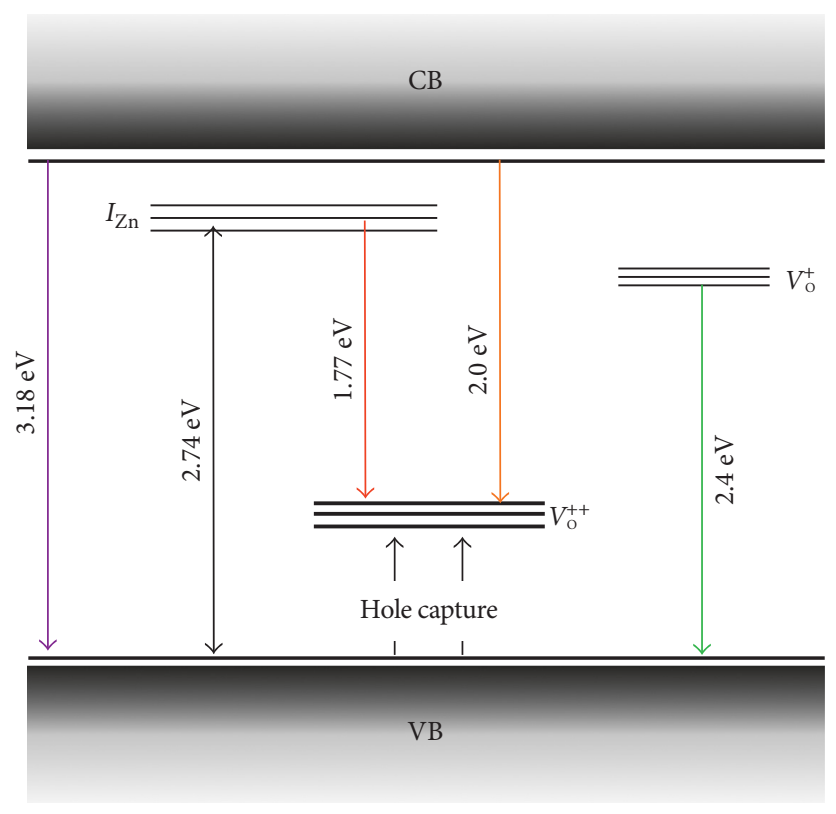

(a)
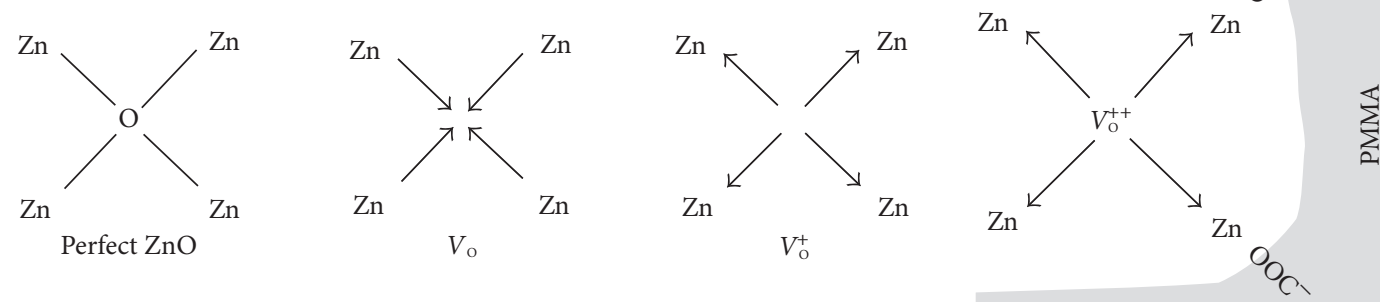

(b)

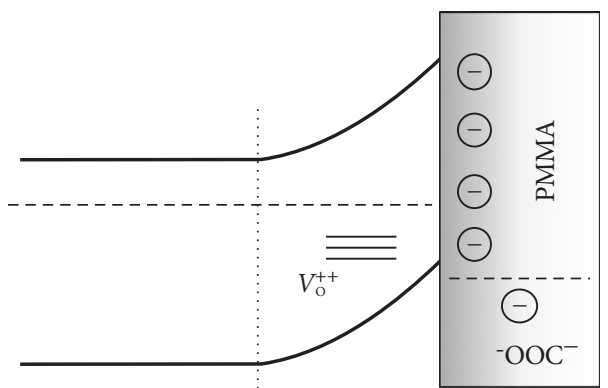

Bulk $\mathrm{ZnO}$ Interfaces

(c)

Figure 5: (a) PL mechanism in the ZnO-PMMA composite; (b) stabilization of $V_{O}^{++}$induced by PMMA matrix; (c) band bending at ZnO-PMMA interfaces.

and valence holes. The orange $(2.0 \mathrm{eV})$ and red $(1.77 \mathrm{eV})$ emission is attributed to recombination between holes being trapped at $V_{\mathrm{O}}^{++}$states and electron residing at $I_{\mathrm{Zn}}$ related states and conduction band edge, respectively. The ionized oxygen vacancies effectively manifest at $\mathrm{ZnO}$ NPs grain boundaries as discussed previously from the TEM image of $\mathrm{ZnO}$ NPs in
Figure 2(d). The hybridization between $I_{\mathrm{Zn}}$ and charged $V_{\mathrm{O}}$ states varied their energy levels within the bandgap giving rise to a broad emission from 450 to $800 \mathrm{~nm}$ as seen in Figure 3(c). This emission feature was still observed in the ZnO-PMMA composite with 1 wt.\% of $\mathrm{ZnO}$ where the grain boundary among the $\mathrm{ZnO}$ phase is still significant (Figure 4(d)). In 
addition to the grain boundary, $\mathrm{Zn}-\mathrm{OH}$ groups on the surfaces of $\mathrm{ZnO}$ NPs (Figure 3(a)) also contribute to the broad orange emission of $\mathrm{ZnO}$ NPs [34].

Now, we are going to explain the enhanced red emission observed in ZnO-PMMA with 0.6 wt.\% of $\mathrm{ZnO}$ (Figure 4(d)) by using a band-bending model that is schematically illustrated in Figure 5(c). Theoretical calculation on the local structure of oxygen vacancies shows that, in neutral state $\left(V_{\mathrm{O}}\right)$, four surrounding $\mathrm{Zn}$ atoms relax inward by $12 \%$ of the equilibrium $\mathrm{Zn}-\mathrm{O}$ bond while in $V_{\mathrm{O}}^{+}$and $V_{\mathrm{O}}^{++}$states these atoms relax outward by $3 \%$ and $23 \%$, respectively [2]. The relaxation direction is depicted in Figure 5(b). In the present study, the ZnO-PMMA composite was prepared under ultrasonication conditions, which can efficiently induce the formation of - $\mathrm{COOH}$ groups within PMMA matrix and the reaction: $\mathrm{Zn}-\mathrm{OH} \pm \mathrm{COOH} \rightarrow \mathrm{Zn}-\mathrm{OOC}+\mathrm{H}_{2} \mathrm{O}$ [27]. The $\mathrm{Zn}$-OOC bonds between $\mathrm{ZnO}$ NPs and PMMA matrix stabilized chemically the $V_{\mathrm{O}}^{++}$states. The absence of the vibrational bands of surface $\mathrm{Zn}-\mathrm{OH}$ groups at $3400 \mathrm{~cm}^{-1}$ and $1385 \mathrm{~cm}^{-1}$ in FT-IR spectra of the ZnO-PMMA composite (Figure 3(a)) supports this reaction. Additionally, the negatively charged $-\mathrm{COO}^{-}$groups bend the band of $\mathrm{ZnO}$ upward, resulting in a depletion of the interface region where formation energy of $V_{\mathrm{O}}^{++}$is efficiently reduced [32, 33, 35]. We suppose that the band bending increased the concentration of $V_{\mathrm{O}}^{++}$states to an extent that captured most of photoexcited holes, and at the same time they, in turn, increased the concentration of $I_{\mathrm{Zn}}$ related states via Coulomb interaction. As a result, recombination between electrons and holes being trapped at $I_{\mathrm{Zn}}$ and $V_{\mathrm{O}}^{++}$states, respectively, became the major emission channel in the ZnO-PMMA composite as seen in Figure 4(d).

\section{Conclusion}

By using ultrasonic irradiation, we were able to prepare $\mathrm{ZnO}$ particles with different shape, from spherical particles to hexagonal rod-like structures, by simply changing the concentration of the zinc acetate precursor. The resultant $\mathrm{ZnO}$ NPs showed a broad orange emission originated from $I_{\mathrm{Zn}}$ and $V_{\mathrm{O}}$ trapping defects together with a low-intensity, band-edge peak in the UV region. Increases in $I_{\mathrm{Zn}}$ and $V_{\mathrm{O}}^{++}$ concentrations induced by band-bending effects as embedding $\mathrm{ZnO}$ NPs into PMMA matrix accounted for the enhanced red emission in the $\mathrm{ZnO}$-PMMA composite. The results demonstrated in this study can be utilized for the development of $\mathrm{ZnO}$ nanostructures as well as their composite for diverse lighting applications.

\section{Conflicts of Interest}

The authors declare that they have no conflicts of interest.

\section{Acknowledgments}

This research was supported by Hanoi Pedagogical University No. 2 under Grant number C.2017-18-05.

\section{References}

[1] R. Azmi, H. Aqoma, W. T. Hadmojo et al., "Low-temperatureprocessed 9\% colloidal quantum dot photovoltaic devices through interfacial management of $\mathrm{p}-\mathrm{n}$ heterojunction," Advanced Energy Materials, vol. 6, no. 8, p. 1502146, 2016.

[2] A. Janotti and C. G. Van de Walle, "Fundamentals of zinc oxide as a semiconductor," Reports on Progress in Physics, vol. 72, no. 12, p. 126501, 2009.

[3] K. Mun, C. Wei, K. Sing, and J. Ching, "Recent developments of zinc oxide based photocatalyst in water treatment technology: a review," Water Research, vol. 88, pp. 428-448, 2016.

[4] X. Chen, Z. Wu, D. Liu, and Z. Gao, "Preparation of ZnO photocatalyst for the efficient and rapid photocatalytic degradation of azo dyes," Nanoscale Research Letters, vol. 12, no. 1, p. 143, 2017.

[5] P. Felbier, J. Yang, J. Theis, R. W. Liptak, and A. Wagner, "Highly luminescent $\mathrm{ZnO}$ quantum dots made in a nonthermal plasma," Advanced Functional Materials, vol. 24, no. 14, pp. 1988-1993, 2014.

[6] A. Sanmugam, D. Vikraman, S. Venkatesan, and H. J. Park, "Optical and structural properties of solvent free synthesized starch/chitosan-ZnO nanocomposites," Journal of Nanomaterials, vol. 2017, Article ID 7536364, 8 pages, 2017.

[7] A. Kolodziejczak-Radzimska and T. Jesionowski, "Zinc oxide-from synthesis to application: a review," Materials, vol. 7, no. 4, pp. 2833-2881, 2014.

[8] Y. Azizian-Kalandaragh, A. Khodayari, and M. Behboudnia, "Ultrasound-assisted synthesis of $\mathrm{ZnO}$ semiconductor nanostructures," Materials Science in Semiconductor Processing, vol. 12, no. 4-5, pp. 142-145, 2009.

[9] D. Haciu and Ö. Birer, "Sonochemical zinc oxide and layered hydroxy zinc acetate synthesis in fenton-like reactions," Ultranosics Sonochemistry, vol. 35, pp. 326-332, 2017.

[10] M. K. Poddar, S. Sharma, S. Pattipaka, D. Pamu, and V. S. Moholkar, "Ultrasound-assisted synthesis of poly (MMA-co-BA)/ZnO nanocomposites with enhanced physical properties," Ultranosics Sonochemistry, vol. 39, pp. 782791, 2017.

[11] A. Phuruangrat, O. Yayapao, T. Thongtem, and S. Thongtem, "Synthesis and characterization of europium-doped zinc oxide photocatalyst," Journal of Nanomaterials, vol. 2014, Article ID 367529, 9 pages, 2014.

[12] K. S. Suslick, "Sonochemistry," Science, vol. 247, no. 4949, pp. 1439-1445, 1990.

[13] H.-M. Xiong, "Photoluminescent $\mathrm{ZnO}$ nanoparticles modified by polymers," Journal of Materials Chemistry, vol. 20, no. 21, pp. 4251-4262, 2010.

[14] L. Zhang, L. Yin, C. Wang, Y. Qi, and D. Xiang, "Origin of visible photoluminescence of $\mathrm{ZnO}$ quantum dots: defectdependent and size-dependent," Journal of Physical Chemistry C, vol. 114, no. 21, pp. 9651-9658, 2010.

[15] R. Raji and K. G. Gopchandran, "ZnO nanostructures with tunable visible luminescence: effects of kinetics of chemical reduction and annealing," Journal of Science: Advanced Materials and Devices, vol. 2, no. 1, pp. 51-58, 2017.

[16] X. Tang, E. Shi, G. Choo, L. Li, J. Ding, and J. Xue, "Synthesis of $\mathrm{ZnO}$ nanoparticles with tunable emission colors and their cell labeling applications," Chemistry of Materials, vol. 22, pp. 3383-3388, 2010.

[17] V. Kumar, H. C. Swart, O. M. Ntwaeaborwa et al., "Origin of the red emission in zinc oxide nanophosphors," Materials Letters, vol. 101, pp. 57-60, 2013. 
[18] H. Hong, F. Wang, Y. Zhang et al., "Red fluorescent zinc oxide nanoparticle: a novel platform for cancer targeting," ACS Applied Materials \& Interfaces, vol. 7, pp. 3373-3381, 2015.

[19] D. Sun, N. Miyatake, and H. Sue, "Transparent PMMA/ZnO nanocomposite films based on colloidal $\mathrm{ZnO}$ quantum dots," Nanotechnology, vol. 18, no. 21, p. 215606, 2007.

[20] M. R. Parra and F. Z. Haque, "Aqueous chemical route synthesis and the effect of calcination temperature on the structural and optical properties of $\mathrm{ZnO}$ nanoparticles," Journal of Materials Research and Technology, vol. 3, no. 4, pp. 363-369, 2014.

[21] T. Alammar and A.-V. Mudring, "Sonochemical synthesis of $0 \mathrm{D}, 1 \mathrm{D}$, and $2 \mathrm{D}$ zinc oxide nanostructures in ionic liquids and their photocatalytic activity," ChemSusChem, vol. 4, no. 12, pp. 1796-1804, 2011.

[22] S. S. Warule, N. S. Chaudhari, B. B. Kale, and M. A. More, "Novel sonochemical assisted hydrothermal approach towards the controllable synthesis of $\mathrm{ZnO}$ nanorods, nanocups and nanoneedles and their photocatalytic study," CrystEngComm, vol. 11, pp. 2776-2783, 2009.

[23] J. Wang and L. Xiang, "Formation of $\mathrm{ZnO}$ rods with varying diameters from $\varepsilon-\mathrm{Zn}(\mathrm{OH})_{2}$," Journal of Crystal Growth, vol. 401, pp. 279-284, 2014.

[24] M. Skompska and K. Zarębska, "Electrodeposition of $\mathrm{ZnO}$ nanorod arrays on transparent conducting substrates-a review," Electrochimica Acta, vol. 127, pp. 467-488, 2014.

[25] Y. He, J. Hu, and Y. Xie, "High-efficiency dye-sensitized solar cells of up to $8.03 \%$ by air plasma treatment of $\mathrm{ZnO}$ nanostructures," Chemical Communications, vol. 51, no. 90, pp. 16229-162232, 2015.

[26] B. D. Viezbicke, S. Patel, B. E. Davis, and D. P. B. Iii, "Evaluation of the Tauc method for optical absorption edge determination: $\mathrm{ZnO}$ thin films as a model system," Physical Status Solidi B, vol. 252, no. 8, pp. 1700-1710, 2015.

[27] X. Du, Y. Fu, J. Sun, X. Han, and J. Liu, "Complete UV emission of $\mathrm{ZnO}$ nanoparticles in a PMMA matrix," Semiconductor Science and Technology, vol. 21, no. 8, pp. 10201206, 2006.

[28] L. E. Ocola, A. Connolly, D. J. Gosztola, R. D. Schaller, and A. Yanguas-Gil, "In filtrated zinc oxide in poly(methyl methacrylate): an atomic cycle growth study," Journal of Physical Chemistry C, vol. 121, no. 3, pp. 1893-1903, 2016.

[29] A. B. Djuriši, Y. H. Leung, K. H. Tam et al., "Green, yellow, and orange defect emission from $\mathrm{ZnO}$ nanostructures: influence of excitation wavelength," Applied Physics Letters, vol. 88, no. 10, p. 103107, 2006.

[30] K. Vanheusden, W. L. Warren, C. H. Seager et al., "Mechanisms behind green photoluminescence in $\mathrm{ZnO}$ phosphor powders," Journal of Applied Physics, vol. 79, no. 10, pp. 7983-7990, 1996.

[31] K. Bandopadhyay and J. Mitra, "Zn interstitials and O vacancies responsible for n-type $\mathrm{ZnO}$ : what do the emission spectra reveal?," RSC Advances, vol. 5, no. 30, pp. $23540-$ 23547, 2015.

[32] P. Erhart, K. Albe, and A. Klein, "First-principles study of intrinsic point defects in $\mathrm{ZnO}$ : role of band structure, volume relaxation, and finite-size effects," Physical Review B, vol. 73, no. 20, p. 205203, 2006.

[33] Y. Kim and C. H. Park, "Rich variety of defects in $\mathrm{ZnO}$ via an attractive interaction between $\mathrm{O}$ vacancies and $\mathrm{Zn}$ interstitials: origin of n-type doping," Physical Review Letters, vol. 102, no. 8, p. 086403, 2009.

[34] M. Wang, L. Jiang, E. J. Kim, and S. H. Hahn, "Electronic structure and optical properties of $\mathrm{Zn}(\mathrm{OH})_{2}: \mathrm{LDA}+\mathrm{U}$ calculations and intense yellow luminescence," RSC Advances, vol. 5, no. 106, pp. 87496-87503, 2015.

[35] S. Hariharan and B. Karthikeyan, "Band bending effect induced non-enzymatic highly sensitive glucose sensing in $\mathrm{ZnO}$ nanoparticles," Journal of Luminescence, vol. 183, pp. 1-6, 2017. 


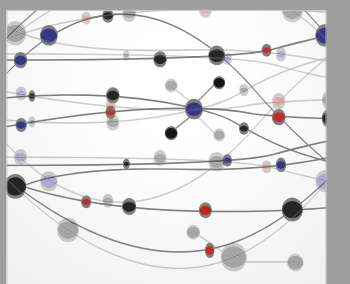

The Scientific World Journal
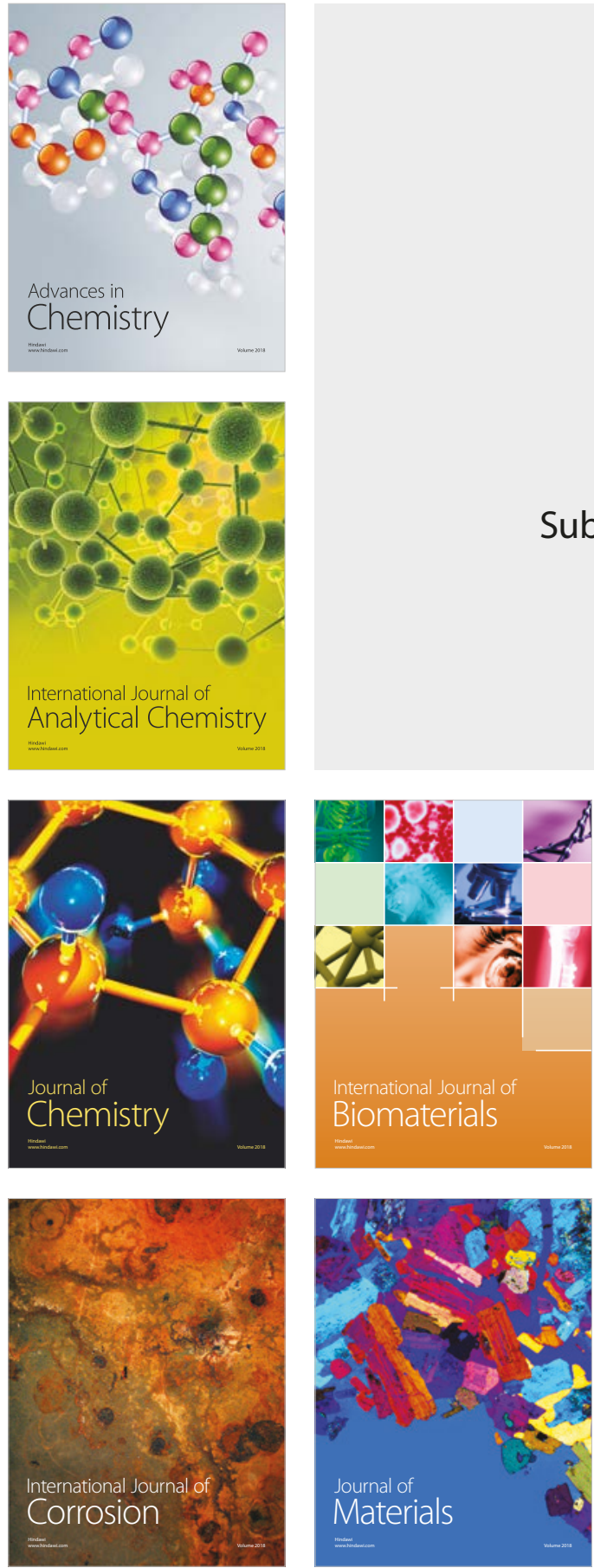

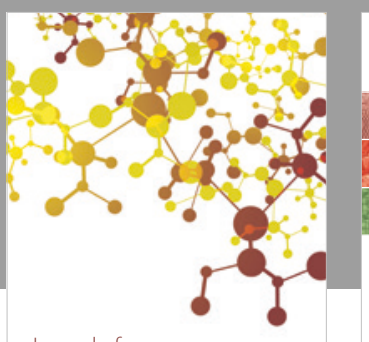

Journal of

Applied Chemistry
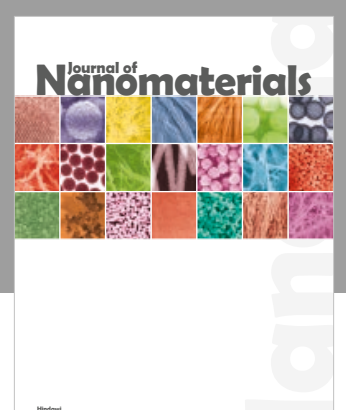

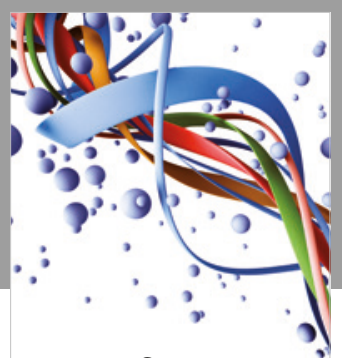

Scientifica

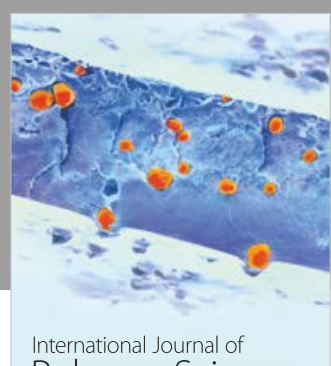

Polymer Science

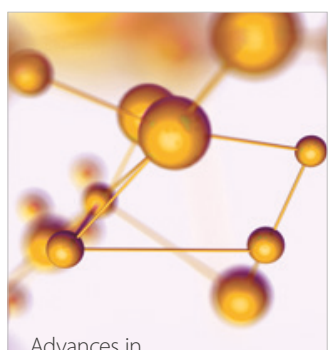

Physical Chemistry
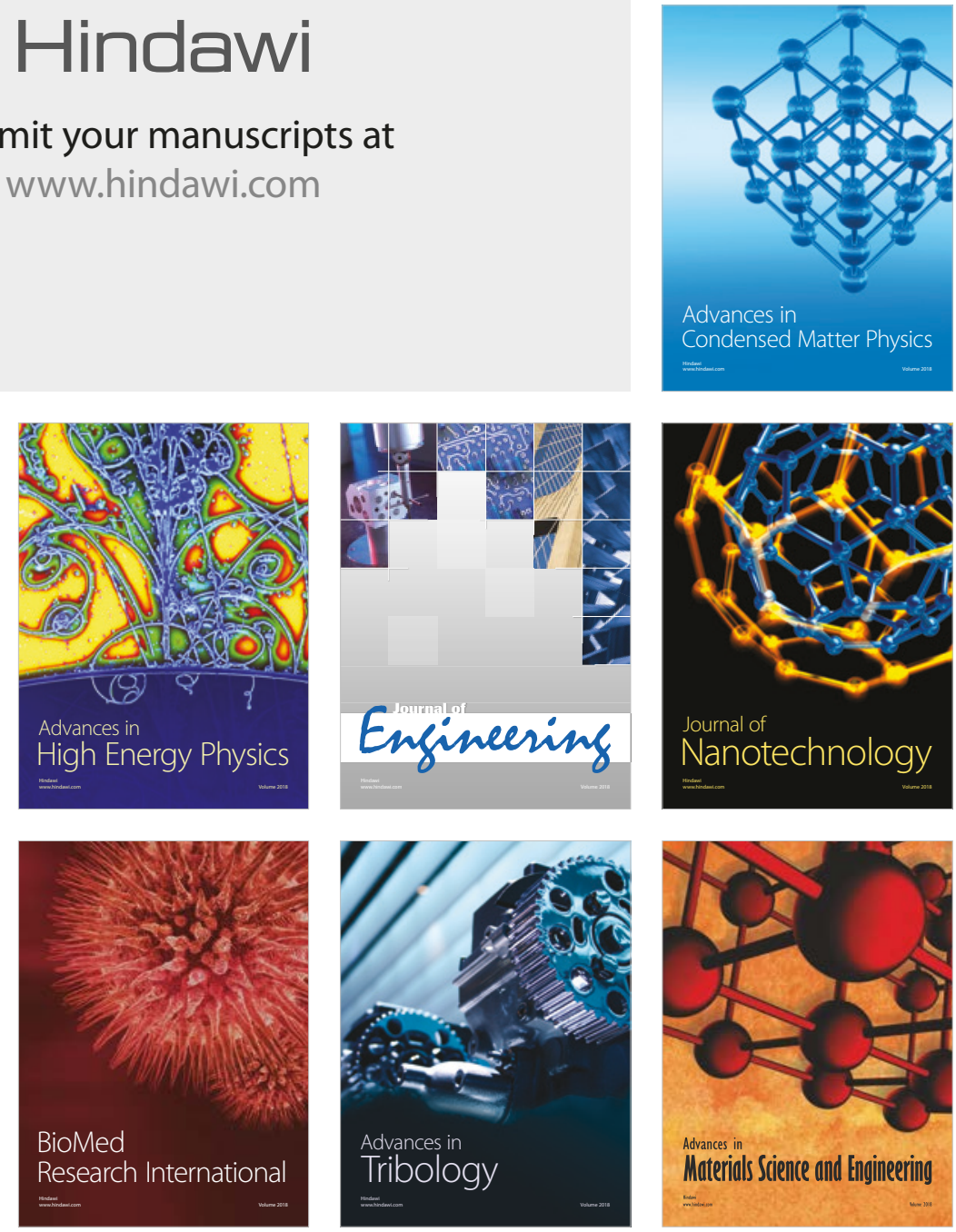